proportion (55/932) of all cases of cerebral palsy in that period. The aetiology of cerebral palsy in low birthweight infants in multiple births is probably similar to that in singletons.

In a few cases a cotwin died antenatally, with resulting brain damage in the surviving twin. This is seen in our data and has been known for many years. ${ }^{2}$ As rates of multiple births are rising it is important to keep monitoring the rates of cerebral palsy in these births.

We agree with Judith Glynn and David Leon's comments. It is impossible from our epidemiological data to ascertain when brain damage occurred. We agree that in infants of $1500 \mathrm{~g}$ who develop cerebral palsy the sequence could have started antenatally, perinatally, or postnatally and the epidemiological picture would be similar. We recently reviewed this.

In normal birthweight infants it is also likely that there has been a shift from deaths to survivors with cerebral palsy, and possibly from survivors with cerebral palsy to non-handicapped survivors. We still believe that our data, in conjunction with other data to which we referred in our paper, can be interpreted as suggesting that birth asphyxia is not the main cause of cerebral palsy.

FIONA STANLEY

Department of Paediatrics,

University of Western Australia,

Perth,

Australia

1 Petterson B, Stanley F, Henderson D. Cerebral palsy in multiple births in Western Australia: genetic aspects. Am $\mathcal{f}$ Med Genet 1990;37:346-51.

2 Melnich M. Brain damage in survivor after in utero death of monozygous cotwin. Lancet 1977;ii:1287.

3 Stanley FJ. Survival and cerebral palsy in low birth weight infants: implications for perinatal care. Paediatric and Perinatal Epidemiology 1992;6:298-310.

\section{Juvenile myoclonic epilepsy}

EDITOR, - In their editorial P L Timmings and A Richens state that juvenile myoclonic epilepsy occurs in one in 10 of all cases of epilepsy.' This is a gross overestimate. Community based studies have shown a frequency of no more than $2 \%,{ }^{24}$ and the paper that Timmings and Richens quote in support of their figure of one in 10 actually gives a figure of $4-6 \% .^{5}$ This is not an insignificant issue, as misdiagnosis is rife and may lead to incorrect treatment.

S D SHORVON $J$ W A S SANDER

National Hospital - Chalfont Centre for Epilepsy,

Chalfont St Peter,

Buckinghamshire SL9 0RJ

1 Timmings PL, Richens A. Juvenile myoclonic epilepsy. $B M \mathcal{f}$ 1992;305:4-5. (4 July.)

2 Juul-Jensen P, Foldspang A. Natural history of epileptic Juul-Jensen P, Foldspang A. Nat
seizures. Epilepsia 1983;24:297-312.

3 Keranen T, Sillanpaa A, Riekkinen P. Distribution of seizures types in an epileptic population. Epilepsia 1988;29:1-7.

4 Sander JWAS, Hart YM, Johnson AL, Shorvon SD. The national general practice study of epilepsy: newly diagnosed epileptic seizures in a general population. Lancet 1990;336: $1267-71$

5 Janz D. Epilepsy with impulsive petit mal. Acta Neurol Scand 1985;72:449-59.

AUTHORS' REPLY, - Discussion about the incidence and prevalence of juvenile myoclonic epilepsy is important. In our original draft we observed that "interest in juvenile myoclonic epilepsy has increased steadily and the reported incidence of $2 \cdot 1 \%^{1}$ among all epilepsy (1957) has risen to $11.9 \%^{2}$ (1984)." This was reduced to "accounts for about 1 in 10 cases of epilepsy" in the final version. As S D Shorvon and J W A S Sander observe these figures are derived from hospital based groups, and the figures in unselected community based services may be lower. We also note, however, that (a) physicians unfamiliar with a condition are less likely to diagnose it, and this clearly applies to juvenile myoclonic epilepsy as the mean time from presentation to correct diagnosis is measured in years ${ }^{3-6}$; and $(b)$ including paediatric patients in any survey of the prevalence of juvenile myoclonic epilepsy will tend to dilute the figure (the figure of $11.9 \%$ is based on an "almost exclusively adult population").

In a review Penry et al stated that juvenile myoclonic epilepsy represents 4-6\% of all epilepsy ${ }^{3}$ but did not give any original figures, preferring to refer to Janz and Christian. ${ }^{12}$ In another review of juvenile myoclonic epilepsy Dreifuss stated that it affects about $7 \%$ of all adolescents and adults with epilepsy, but, again, no new data are cited.? Interestingly, in a recently reported series of 180 patients referred over 21 months to a "new epilepsy" clinic in Britain the prevalence was $8 \cdot 3 \%$. $^{6}$

We believe that juvenile myoclonic epilepsy makes up $5-10 \%$ of all epilepsy in adolescents and adults and that the papers referred to by Shorvon and Sander (with prevalences of around 2\%) may be underestimating its frequency because of underrecognition and inclusion of paediatric data. ${ }^{8.10}$

ALAN RICHENS P L TIMMINGS

Department of Pharmacology and Therapeutics,

University of Wales College of Medicine,

Cardiff CF4 $4 \mathrm{XN}$

1 Janz D, Christian W. Impulsiv-petit mal. Deutsche Zeitschrift fü Nervenheilkunde 1957;19:155-82.

2 Janz D. Epilepsy with impulsive peti mal. Acta Neurol Scand 1985;72:449-59.

3 Penry JK, Dean JC, Riela AR. Juvenile myoclonic epilepsy: long-term response to therapy. Epilepsia $1989 ; 30$ (suppl 4): S19-23.

4 Obeid T, Panayiotopoulos CP. Juvenile myoclonic epilepsy: study in Saudi Arabia. Epilepsia 1988;29:280-2.

5 Thomas D, Riela AR, Penry JK. Epilepsy and diagnosis of juvenile myoclonic epilepsy. Ann Neurol 1989;26:162.

6 Grunwald RA. Chroni E, Panayiotopoulos CP. Delayed diagnosis of juvenile myoclonic epilepsy. I Neurol Neurosurg

7 Dreifuss FE. Juvenile myoclonic epilepsy: characteristics of a primary generalised epilepsy. Epilepsia 1989;30(suppl 4): S1-7.

8 Juul-Jensen P, Foldspang A. Natural history of epileptic seizures. Epilepsia 1983;24:297-312.

9 Keranen T, Sillanpaa A, Riekkinen P. Distribution of seizure types in an epileptic population. Epilepsia 1988;29:1-7.

10 Sander JWAS, Hart YM, Johnson AL, Shorvon SD. The national general practice study of epilepsy: newly diagnosed epileptic seizures in a general population. Lancet 1990;336: $1267-71$.

\section{Selective serotonin reuptake inhibitors}

EDITOR,-The correspondence ${ }^{12}$ on J Guy Edwards's editorial on selective serotonin reuptake inhibitors ${ }^{3}$ requires comment. Debbie Harrison chides Edwards for mentioning single reports of adverse reactions, ${ }^{1}$ but such reports are vital as postmarketing surveillance and require attention. Harrison and $\mathrm{S} O$ Fradd $^{2}$ criticise Edwards for mentioning cost. This is not surprising from Harrison, who is an employee of the main pharmaceutical company in this field, and it is inappropriate for her to reprimand Edwards for having made up his mind already about the role of selective serotonin reuptake inhibitors - no more so than Harrison and her company have.

Fradd's outlook is particularly disappointing. Fradd oversimplifies the problem, implying that selective serotonin reuptake inhibitors are without serious side effects while tricyclic antidepressants, with which we have long experience, are highly toxic. To suggest that doctors should not consider the economic consequences of their prescribing to society as well as to individual patients is an outmoded concept that doctors should abandon. A professional decision to prescribe only selective serotonin reuptake inhibitors would cost $£ 100-150$ million a year, with inevitable consequences for other NHS services.

In reality, neither tricyclic antidepressants nor selective serotonin reuptake inhibitors are ideal for depression: both are slow to produce a benefit, and neither is effective in more than about $80 \%$ of cases. The selective serotonin reuptake inhibitors are a relatively new class of antidepressant whose full pharmacology and role in treatment are not yet known. ${ }^{45}$ To advocate a wholesale move to using them as first choice antidepressant treatment ${ }^{6}$ rather than more established and less expensive drugs, solely because of their safety in overdose, is unreasonable on medical, ethical, and economic grounds.

Should a doctor treat a depressed patient with a tried and trusted remedy or with a less established drug? The family of a patient who commits suicide by any means (and not just drug overdose) might well have a better case if the doctor prescribed the less established treatment; of course, a doctor should weigh each case on its own merits. In a court case the gold standard would probably be what the doctor's peers would reasonably do in the circumstances.

Edward's conclusion that selective serotonin reuptake inhibitors should be reserved for selected patients represents a balanced view of the current state of knowledge, and Harrison's contention that these drugs are an enormous advance in the treatment of depression is unwarranted.

T WALLEY

Department of Pharmacology and Therapeutics,

Liverpool University,

PO Box 147

Liverpool L69 3BX

1 Harrison D Selective serotonin reuptake inhibitors. $B M \mathcal{F}$ 1992;305:366. (8 August.)

Fradd SO Selective serotonin reuptake inhibitors. $B M 7$ 1992; 305:366. (8 August.)

Edwards JG. Selective serotonin reuptake inhibitors. $B M \mathcal{Y}$ 1992;304:1644-6. (27 June.)

4 Potters WZ, Rudorfer MV, Manji H. The pharmacologica treatment of depression. N Engl f Med 1991;325:633-42.

Freeling P, Tylee A, Paykel E. Which antidepressant? Br $\mathcal{f ~ G e n}$ Pract 1991;42:302-3.

Matthews K, Eagles J. Which antidepressant? $\mathrm{Br} \mathcal{F}$ Gen Pract $1991 ; 41: 123-5$

\section{Value of Dundee coronary risk-disk}

EDITOR, - Tony Randall and colleagues report that when they used the Dundee coronary risk-disk on the population of south Bedfordshire it failed to detect high risk subjects.' According to the registrar general's figures, the coronary risk for south Bedfordshire makes it, on the basis of crude death rates, the eighth safest health district in the land: Milton Keynes, west Berkshire, Huntingdon, Oxfordshire, west Surrey, Parkside, and north west Surrey have lower crude death rates. Tayside, on the other hand, is 15 th from the top of Britain's 220 health districts in terms of coronary risk and is far more typical of the country as a whole.

Of the seven low risk areas, only three (including south Bedfordshire) have low age standardised rates - that is, the populations are untypically young. Thus a schedule for assessing risk such as the Dundee score will miss more of the single risk factors in a young population than in a population of average age distribution because one of the variables contributing to the score is age; in south Bedfordshire this is artificially low. Other factors must operate in Parkside, Berkshire, Oxford, and Cambridge: all have age standardised coronary death rates $63 \%$ of Tayside's rate.

A series of cholesterol concentrations measured in this practice gave an average of $6.1 \mathrm{mmol} / \mathrm{l}$, so other factors in southern England must operate to reduce the coronary risk and the Dundee disk does 